\title{
Örgütlerde Dedikodunun İşyeri Morali ve Çalışma Eforu Üzerindeki Etkisi (The Affect of Gossip in Organizations on Workplace Morale and Work Effort)
}

\section{Elif BİLGINOĞLU iD a Uğur YOZGAT iD b}

a İstanbul, Türkiye. elifb@ada.net.tr

b Nişantaşı Üniversitesi, İstanbul, Türkiye. ugur.yozgat@nisantasi.edu.tr

\begin{tabular}{|c|c|}
\hline MAKALE BİLGİSİ & ÖZET \\
\hline $\begin{array}{l}\text { Anahtar Kelimeler: } \\
\text { Dedikodu } \\
\text { Örgütlerde dedikodu } \\
\text { İşyeri morali } \\
\text { Çalışma eforu }\end{array}$ & $\begin{array}{l}\text { Amaç - Dedikodu çalışma ortamında huzursuzluk yaratmakta ve örgütlerde moral bozukluğuna } \\
\text { sebep olmakta, dedikoduyu yapanlar ve dedikoduya konu olanların çalışmasını engellemesinin } \\
\text { yanı sıra çalışma eforlarının düşmesine de yol açmaktadır. Yapılan araştırmalarda dedikodu ve } \\
\text { etkilerini anlamanın önemli olduğu ve örgütsel dedikodunun rolünün örgütler, yöneticileri ve } \\
\text { işgücü üzerindeki etkileri üzerine titizlikle yapılacak araştırmalara ihtiyaç duyulduğu belirtilmiş } \\
\text { olmakla birlikte bu konunun araştırmalarda nadiren ele alındığı birçok araştırmacı tarafından } \\
\text { vurgulanmıştır. Bu çalışma, literatürdeki bu boşluğu doldurarak örgütlerde dedikodunun, işyeri } \\
\text { morali ve çalışma eforu üzerindeki etkisinin araştırılmasını amaçlamaktadır. }\end{array}$ \\
\hline $\begin{array}{l}2020 \\
\text { Revizyon Tarihi } 25 \text { Temmuz } \\
2020 \\
\text { Kabul Tarihi } 10 \text { Eylül } 2020\end{array}$ & $\begin{array}{l}\text { Yöntem - Çalışmada öncelikle literatür taraması yapılarak kavramsal çerçeve oluşturulmuş ve genel } \\
\text { kabul görmüş olan ölçeklerden anket formu hazırlanmıştır. Araştırma verileri İstanbul'da özel } \\
\text { sektörde üretim alanında faaliyet gösteren on işletmeden kolayda örnekleme yöntemi ile } 14 \text { Ekim - } \\
22 \text { Aralık } 2019 \text { tarihleri arasında toplanmış, en az üç yıldır aynı işyerinde çalışanlardan gelen } \\
\text { eksiksiz doldurulmuş } 397 \text { anketten elde edilen veriler SPSS istatistik programı ile çözülenmiş, elde } \\
\text { edilen verilere güvenilirlik analizi, faktör analizi, korelasyon ve regresyon analizi yapılmış, } \\
\text { hipotezler test edilmiştir. }\end{array}$ \\
\hline $\begin{array}{l}\text { Makale Kategorisi: } \\
\text { Araştırma Makalesi }\end{array}$ & $\begin{array}{l}\text { Bulgular - Araştırma sonuçları örgütlerde dedikodunun hem işyeri morali hem de çalışma eforu } \\
\text { üzerinde negatif etkisi olduğunu, aynı zamanda işyeri moralinin örgütlerde dedikodu ve çalışma } \\
\text { eforu arasındaki ilişkide düzenleyici etkisi olduğunu ortaya koymaktadır. } \\
\text { Tartışma - Dedikodu hayatın bir parçası olduğu için ne yöneticiler ne de insan kaynakları } \\
\text { departmanları örgütlerde dedikoduyu tamamen ortadan kaldıramasa da örgüt içindeki sağlam } \\
\text { iletişim kanallarını kullanarak, çalışanlara dedikodunun potansiyel zararlarına dair eğitimler } \\
\text { vererek ve dedikodu konusunda yaptırımlar içeren örgüt politikaları uygulayarak örgütte } \\
\text { dedikoduyu yapan ve yayan kişilerin kontrol altına alınması ve engellenmesi adına adımlar } \\
\text { atılabilmektedir. }\end{array}$ \\
\hline
\end{tabular}

\begin{tabular}{ll}
\hline ARTICLE INFO & ABSTRACT \\
\hline $\begin{array}{l}\text { Keywords: } \\
\text { Gossip }\end{array}$ & $\begin{array}{l}\text { Purpose - Gossip harms organizations due to the several negative consequences it causes in the } \\
\text { work environment. It creates discomfort in the working environment and causes low morale in } \\
\text { organizations. In addition to preventing those who gossip and those who are subject to gossip from } \\
\text { Workplace morale }\end{array}$ \\
$\begin{array}{l}\text { Working, it also leads to a decrease in the work effort of employees by the low morale it creates. } \\
\text { Previous research has revealed that understanding gossip mechanism and its effects is important } \\
\text { for organizational practitioners and there is a need for the development of a more rigorous analysis } \\
\text { of the role of organizational gossip with reference to the effects it can have for the organization as a }\end{array}$ \\
$\begin{array}{l}\text { whole, its managers and its workforce. However, there is a lack of academic research addressing the } \\
\text { gossip in organizations. This study aims to fill this gap by examining the effect of gossip in }\end{array}$ \\
$\begin{array}{l}\text { Revised 25 July 2020 } \\
\text { organizations on workplace morale and work effort. }\end{array}$ \\
$\begin{array}{l}\text { Design/methodology/approach - In the study, a conceptual framework was formed by searching } \\
\text { the literature and a questionnaire was prepared by using well accepted scales. Data was collected } \\
\text { from ten companies operating in manufacturing sector in Istanbul using convenience sampling } \\
\text { method between October 14th and December 22nd, 2019. 397 fully filled questionnaires returned from } \\
\text { employees, working at least for three years in the same company, have been analyzed with SPSS } \\
\text { sesearch Article }\end{array}$ \\
$\begin{array}{l}\text { statistics program. Finally, reliability, factor, correlation and regression analysis were performed on } \\
\text { the obtained data, and hypotheses were tested. }\end{array}$ \\
$\begin{array}{l}\text { Findings - The results reveal that gossip in organizations has a negative effect on both workplace } \\
\text { morale and work effort, and additionally workplace morale has a moderating effect on the } \\
\text { relationship between gossip in organizations and work effort. }\end{array}$ \\
\hline
\end{tabular}


Discussion - Today gossip in organizations is a bigger problem than ever before. Although gossip is a part of life and thus neither the managers nor the human resources departments can completely eliminate gossip in organizations, they can take steps to control and stop the people who gossip and spread gossip in the organization by using strong communication channels within the organization, by training the employees about the potential harms of the gossip, and by applying organizational policies that contain sanctions about gossip.

\section{GİRIŞ}

Dedikodu sosyal yaşamda çok yaygındır (Waddington, 2012: 1) ve muhtemelen birçok toplumda ve kültürde vardır (Baumeister vd., 2004). Yapılan araştırmalar sohbetlerin yaklaşık \%65 ila \%90'ını dedikodunun oluşturduğunu (Dunbar vd., 1997; Emler, 1994), işyerlerinde ise sohbetlerin \%90 kadarı dedikodu olarak nitelendirilirken, tüm iş e-postalarının yaklaşık \%15'inin dedikodu olarak sınıflandırılabileceğini ortaya koymaktadır (Bassuk ve Lew, 2016: 3).

Dedikodu genellikle başkalarını manipüle etmeyi ve onları kötü niyetli bir şekilde etkilemeyi amaçlayan yalnızca kendi kendine hizmet eden davranış olarak görülmektedir (Beersma ve Van Kleef, 2012: 2641). Tarih boyunca klişeleşmiş bir şekilde kadınlar arasındaki kötüleyici konuşmalar olarak görülmüş olan dedikodu, örgütsel açıdan ise genellikle güvenilmez hatta tehlikeli bir iletişim şekli olarak görülmektedir (Waddington ve Michelson, 2007). Dedikodu, doğası gereği, sadece orada olmayan bir kişi hakkında olumsuz bilgileri aktarmakla ilgili olmasa da (Grosser vd., 2010: 179; McAndrew, 2019: 174; Saunders, 1999: 268), çoğu toplumda olumsuz bir çağrışım yapmaktadır (Zimmerman, 2008). Dinlerin çoğu gereksiz dedikodulara karşı uyarmaktadır ve dedikodu tarih boyunca verilmiş çeşitli cezaların nedeni olmuştur (Grosser vd., 2010: 178). Dedikoduya dair ortak görüşün onun hem konuşana hem dinleyene hem de kurbana zarar verdiği yönünde olması da (Kennedy, 2014) onun övgüye değer, derin ya da önemli insan davranışlarından biri olmadığının bir göstergesidir (Emler, 1994: 118). Dedikodu çok kınanmakla birlikte aynı zamanda sıkça başvurulan bir iletişim şekli olduğu için (Erdogan vd., 2015: 193) herkeste görülen ve herkesi etkileyen bir davranış olarak tüm sosyal varlıklar için önemlidir (Chulguen vd., 2014).

İşyerleri dedikodu için verimli bir ortam sağlamaktadırlar (Bowden, 2019; Farley vd., 2010: 361). Çalışanlar en güncel söylentiler hakkında konuşmak ve spekülasyon yapmak için mesailerinden önemli bir zamanı harcamaktadırlar (Akande ve Odewale, 1994: 27). Tüm ortamlar için zehirli olarak nitelendirilebilecek olan dedikodu, özellikle çalışma ortamlarında çok etkilidir (Campbell, 2016). Dedikodular kültürün sıkıntılarıdır. Dedikodular sayesinde o anda örgütte gerçekleşen isimler, tarihler, maaşlar ve olaylar hakkında bilgi almak mümkün olabilmektedir. Çoğu kişi dedikodu diline temkinli yaklaşıyor olmakla birlikte, önemsiz günlük olaylar, dedikodular tarafından taşındığı için ve diğer kişiler hakkında sürekli yeni haberler almaksızın çoğu örgütte yaşam oldukça sıkıcı olacağı için dedikoduya değer verilmektedir (Deal ve Kennedy, 1982: 91). Ancak unutulmaması gerekir ki hiçbir şey dedikodudan daha hızlı bir şekilde düşmanca bir çalışma ortamı yaratamaz. Başkalarının kendisi hakkında konuştuğunu bilmek hedef olan kişiye kendini kötü hissettirmektedir ve başkalarının arkasından konuşmak potansiyel olarak yıkıcı etkilere sahiptir (Jones vd., 2007: 183).

Yapılan araştırmalarda dedikodu mekanizması ve etkilerini anlamanın örgütsel uygulayıcılar için önemli olduğu (Ben-Hador, 2019) ve örgütsel dedikodunun rolünün örgütler, yöneticiler ve işgücü üzerindeki etkileri üzerine titizlikle yapılacak araştırmalara ihtiyaç duyulduğu belirtilmiş (Noon ve Delbridge, 1993) ancak bununla birlikte bu konunun nadiren ele alındığı birçok araştırmacı tarafından vurgulanmıştır (Bencsik vd., 2019: 27; Chulguen vd., 2014; Kniffin ve Wilson, 2010: 150; Liu vd., 2018; Noon ve Delbridge, 1993; Rooks vd., 2011; van Iterson vd., 2011; Wert ve Salovey, 2004a: 76).

Kişilerin dedikodu hakkındaki düşünceleri ve görüşleri genellikle olumsuzdur (Bonner, 2016). Kötü niyetli, yıkıcı ve büyük ölçüde kınanması gereken bir davranış olarak görülen dedikodu çoğu kişi nezdinde kötü bir üne sahiptir (Dunbar, 2004: 100; Farley, 2011: 574); çünkü dedikodularda, daha çok diğer kişilerin faziletlerindense hatalarının tartışılmasından memnuniyet duyulmaktadır (Lanz 1936: 494). Bu yüzden de dedikodu potansiyel olarak yıkıcı sonuçlara sahiptir (Turner vd., 2003); yanılsamalar belirmesine sebep olabilir, ilişkileri yıkabilir ve ortalığı karıştırabilir (Foster, 2004: 78). Yapılan araştırmalar örgütlerde dedikoduyu örgütsel normları ihlal eden, örgütün ve üyelerinin refahını tehdit eden sapkın bir davranış olarak değerlendirmişlerdir (Robinson ve Bennett, 1995). Dedikodu her ne kadar bazı araştırmalarca nadiren zararlı olan hoş, rahatlatıcı, bağ inşa eden bir sosyal etkinlik olarak görülse de (Ben-Ze'ev, 2000: 185; Coady, 
2006: 259; Giardini ve Wittek, 2019: 29; Wert ve Salovey, 2004b: 122-123) genellikle itibarlar1 yerle bir edebilecek, ilişkileri zehirleyebilecek ve kariyerlere son verebilecek tehlikeli bir silah olarak algılanmaktadır (Westen, 1996: 46). Dedikodunun bireysel ve örgütsel sonuçları aynı zamanda olumlu ve olumsuz, kasıtlı ve kasıtsız, önemsiz ve kayda değer olabileceği için, dedikodu birçok anlayış, yorum ve analiz düzeyinde "yönetilecek bir kâbus" oluşturmaktadır (van Iterson vd., 2011: 385).

Brown ve Leigh'in (1996: 358) örgütteki çalışma ortamına dair spesifik algıların araştırılmasının çalışan ve örgüt arasındaki ilişkinin daha fazla çaba ile ilgili önemli yönlerini ortaya çıkaracağına dair iddiasından yola çıkılarak tasarlanan bu çalışmanın amacı örgütlerde dedikodunun, işyeri morali ve çalışma eforu üzerindeki etkisinin araştırılmasıdır. Bu amaçla İstanbul' da özel sektörde çalışan 288 kişi üzerinde anket uygulanmıştır.

Kamu ve özel sektör kuruluşları birbirlerine göre çeşitli farklılıklar göstermektedirler (McKinsey Center for Government, 2017: 15). Günümüzün oldukça rekabetçi iş çevreleri ve çalışma ortamlarında çalışanların ne kadar verimli oldukları büyük önem arz etmektedir (Matteson, 2008: 249). Kurum içinde çalışanlar arasındaki rekabet iş yaşamının kaçınılmaz bir parçası olup yapılan çalışmalar çalışma ortamlarında kişiler arası rekabetin çalışanları motive edebileceğini, çalışanların daha fazla çalışma eforu harcayabileceklerini ve verimliliklerinin artabileceğini ortaya koymaktadır (Gartenstein, 2020; Steinhage vd., 2017). Kurumlar arası rekabet ise daha verimli kurumların, daha az verimli olanlara göre pazar paylarını artırmalarını sağlamakta ve bunun sonucunda zamanla düşük verimliliğe sahip kurumlar yerlerini daha yüksek verimliliğe sahip kurumlara bırakarak pazardan çıkabilmektedirler (CMA Competition \& Market Authority, 2015: 2). Yapılan araştırmalar halkın kamu sektörü çalışanlarının özel sektör çalışanlarına göre daha az çalıştıklarına ve onlardan daha az verimli olduklarına inandığını ortaya koymaktadır (Volcker, 1989). Bu yüzden de kamu çalışanlarının tembel olduklarına dair bir inanış söz konusudur (Cohen vd., 2013; 19; Meier, 1993: 244; Oğuz, 2015). Özel sektördeki kurumlarının sahipleri ya da yöneticileri için çalışan davranışını izlemek ve denetlemek için doğrudan parasal bir teşvik söz konusu olmakla birlikte, kamu sektöründeki yöneticiler için bu faaliyet uğrunda harcayacakları çabaya karşılık daha az kazanç sağlayacakları, verimi düşürecek bir "kamu malı" olarak değerlendirilmektedir (Boyne, 2002). 2000'li yılların başından bu yana dünyadaki gelişmelere paralel olarak ülkemizde de kamu sektöründe performans yönetimi uygulamalarına yer verilmekte ancak bu uygulamalar henüz sistematik ve bütüncül bir bakış açısıyla değerlendirilmemektedirler (Kırılmaz, 2011). Özel sektörde çalışma eforu ve verimliliğin maksimize edilmesine atfedilen önemden (McKinsey, 2006: 11; Moschandreas, 2000; The International Bank for Reconstruction and Development, 1996: 49) yola çıkılarak bu araştırma örneklemin özel sektör çalışanlarından oluşacağı şekilde tasarlanmıştır.

Araştırma sonuçları örgütlerde dedikodunun hem işyeri morali hem de çalışma eforu üzerinde negatif etkisi olduğunu, aynı zamanda işyeri moralinin örgütlerde dedikodu ve çalışma eforu arasındaki ilişkide düzenleyici etkisi olduğunu ortaya koymaktadır.

\section{KAVRAMSAL ÇERÇEVE}

\section{1. Örgütlerde Dedikodu}

Dedikodu "bireyler arasında biçimsel olmayan bir şekilde paylaşılan başkalarının kişisel meseleleri hakkında doğrulanmamış haberler" (Litman ve Pezzo, 2005: 963) ya da "sosyal bir ortamın üyeleri hakkında değer yüklü bilgileri biçimsel olmayan bir şekilde bildirme süreci" (Noon ve Delbridge, 1993: 25) olarak tanımlanmaktadır. Dedikodu tanımındaki ortak boyutlar biçimsel olmayan bir sohbet olması, bir ölçüde gerçekliğe sahip olması ve (genellikle orada bulunmayan üçüncü bir kişiye) kişisel olarak odaklanmış olmasıdır (Mills, 2010: 216). Dedikodularda en sıkça rastlanan konular kişisel özellikler ve huylar, beklenmedik ve tutarsız davranışlar, karakter kusurları, gerçek davranış ve ahlaki iddialar arasındaki tutarsızlıklar, kötü davranışlar, sosyal olarak kabul edilmeyen davranış biçimleri, yetersizlikler, yakışıksızlıklar, ihmaller, varsayımlar, suçlanabilir hatalar, talihsizlikler ve başarısızlıklar olarak sıralanmıştır (Bergmann, 1993: 15-16).

İşyerinde dedikodu "örgüt üyelerinin üçüncü bir kişi hakkında kişisel bilgileri tartışmaları ya da söylentiler yaymaları" (Brady vd., 2017: 3), "bir örgütte genellikle sadece birkaç kişi arasında geçen o örgütün o sırada orada mevcut olmayan başka bir üyesi hakkındaki resmi olmayan ve değerlendirici konuşma" (Kurland ve Pelled, 2000: 429) ya da "bir örgütün bir üyesinin aynı örgütün bir ya da daha fazla üyesine o strada söylenenleri duymak için orada olmayan başka bir üye hakkında yaptığı biçimsel olmayan ve değerlendirici (başka bir deyişle olumlu ya da olumsuz) konuşma" olarak tanımlanmaktadır (Zhou vd., 2019: 1). Dedikodunun "işyeri dedikodusu" olarak 
nitelendirilebilmesi için olaylara ya da koşullara değil bireylere yönelik olması, tabiatı gereği değerlendirici olması, hedef olan kişinin hem dedikoduyu yapan hem de dedikoduyu dinleyen kişi tarafından bilindiği bir sosyal ortamda (ör. örgüt) gerçekleşmesi ve hedef olan kişinin kaynağının kim olduğunu tespit etmesini imkânsız hale getirmese bile zorlaştırması için hedef olan kişinin yokluğunda yayılması gerekmektedir (Wu vd., 2018: 1876). Aslına bakılırsa dedikodu "mevcut sorunun çözülmesine yardımcı olamayan biriyle kurulan verimsiz iletişim" den başka bir şey değildir ve bu tür bir konuşma içinde yer aldığı çalışma ortamını bozmaktadır (Wolmer, 2017).

İşyeri dedikoduları sınır tanımaz. Aynı örgütte çalışan kişilerin etkileşimlerinin ne denli yoğun olduğu göz önünde bulundurulursa, en hassas bilgilerin bile duyulması olasıdır (Burke ve Wise, 2003: 72). İşyeri dedikoduları örgütlerde, özellikle çalışanların iş ilişkilerine zarar verebilir (Vélez Vega, 2017: 50). Bu önemsiz sohbet ve boş çene çalmanın hakkında konuşulan kişiyi olumsuz, kızdırıcı ve utanç verici bir duruma getirmesi dedikodu yapıldığı anlamına gelmektedir ve bu bir tür saldırı ve işyeri şiddeti olarak değerlendirilmektedir (Schwantes, 2017). Örgütlerde dedikodu için "zehirli fisıltı gazetesi" (Baker ve Jones, 1996: 75) ya da "toksik boş laf" benzetmeleri yapılmakta (Waddington, 2012: 117), dedikodu örgütün yönetilemeyen yönü olarak algılanmakta (Gabriel, 1995) ve bununla birlikte örgütlerde dedikoduyu yayan kişiler en olumsuz işyeri karakterleri olarak adlandırılmaktadırlar (McLeod, 2020).

Yapılan araştırmaların sonuçları örgütlerde çalışanlarca tanık olunan etik dışı çalışan eylemlerinden en yaygın olanlarından birinin dedikodu olduğunu (Better Buys, 2017) ve örgütlerde daha çok olumsuz dedikodunun yapıldığını ortaya koymaktadır (Mitra ve Gilbert, 2012). Örgütlerde algılanan olumsuz dedikodular, dedikoduya hedef olan kişinin işyerindeki duygusal tepkileri ve performansı üzerinde çok ciddi etkiler yaratabilmekte (Babalola vd., 2019: 136), kişileri rahatsız etmekte ve kendilerini kötü hissetmelerine neden olmaktadır (Lucas, 2018).

\section{2. İşyeri Morali}

Moral "grup bağlllı̆̆ından ve çeşitli örgütsel değiş̧kenlerden kaynaklanan coşku ve güdü derecesi" (Maguen ve Litz, 2006: 280), "bir çalışanın işi ve çalı̧̧ma ortamı hakkında ne derece iyi hissettiği" (McKnight vd., 2001: 467) ya da "grubun öngörülen faaliyetlerine yönelik olumlu tutum" (Manning, 1991: 455) olarak tanımlanmaktadır. Moral sadece tatmin ya da motivasyondan daha fazlasıdır; bu kavramların karmaşık bir karışımıdır (Motowidlo ve Borman, 1977: 177).

Her çalışanın içinde var olan bir nitelik olan moral, hisler ve duyguları içeren bir ruhsal durumdur ve anlaşılması zor bir özellik olarak görülmektedir. İşe, çalışma ortamına, ekip üyelerine, yöneticilere ve bir bütün olarak örgüte yönelik tutum ve algıyı içermektedir. Çalışanların morallerinin düşük olması, örgüt kültürü, liderlik tarzları, birey ve grup davranışları, sistemler ya da politikalar ve prosedürler de dahil olmak üzere bir işyerinin sayısız yönünü yansıtmakta ve olumsuz yönde etkilemekteyken (Kendrick, 2017: 847), morallerinin yüksek olması genellikle güven, disiplin ve performans gösterme isteği ile ortaya koyulmaktadır (Ali, 2013).

Moralin yüksek olduğu bir işyeri, kişilerin işe gitmeyi gerçekten sevdiği, işlerinden gerçek anlamda zevk aldıkları, bu işlerde sahip oldukları deneyimlerin tadını çıardıkları ve her projede başarılı olmak için gurur, coşku, kendine güven ve güçlü bir motivasyon hissettikleri ve takım eforunun olduğu bir işyeridir (Bruce, 2003: 1). Moral her tür örgütün en önemli performans özelliklerini etkilemektedir. İşyeri moralinin yüksek ya da düşük olması örgütün hedeflerine ulaşma yeteneğini güçlendirmekte ya da zayıflatmaktadır (Bowles ve Cooper, 2009: 107).

Yöneticilerin çalışanların morallerini bir öncelik olarak görmeleri hem örgüt hem de çalışanlar için yarar sağlayacaktır (Craig, 2017). Yapılan araştırmaların sonuçları yöneticilerin, moral düşük olduğu zaman çalışanların sürekli şikayet ederek birbirlerini işten alıkoyduklarını, moral yüksek olduğu zaman ise çalışanların daha fazla çalışmaya istekli hale geldiklerini, mesai bitmiş bile olsa yaptıkları işi bitirene kadar işten çıkmadıklarını, birbirini cesaretlendirdiklerini ve birbirlerine yardım ettiklerini, işyerinde iyileştirmelere dair önerilerde bulunduklarını ve dışarıdaki kişilerle örgütten oldukça olumlu bahsettiklerini belirttiklerini ortaya koymaktadır (Bewley, 1999: 47-48). Yüksek moralli bir işyeri, mükemmelliğe ulaşan ve iş birliği ile katkıda bulunma arzusunu geliştiren, çalışanların sıkı çalışmak konusunda motive oldukları bir ortamdır. Bu ortamlar, yüksek moralin psikolojik ve ticari getirilerini tanıyan akıllı yöneticiler tarafından şekillendirilirler 
(Bruce, 2003: 2). Günümüz iş piyasasında, bir kişinin yeni fırsatları değerlendirerek başka bir örgüte geçmeyi düşünmesi ve iş aramasının birkaç nedeni vardır. Ancak örgütte kalmasını sağlayacak çok az neden vardır ve bu nedenlerin hepsi de tutum ve morale indirgenebilir (Walter, 2010).

Dedikodu toksik ya da sağlıksız örgüt içi ilişkilerini ve örgüt kültürünü daha da kötü bir duruma sokmaktadır (Yakaboski, 2020). Schwantes'in (2017) "Küçük bir dedikodu ordusu, bir şirketin moralini çabucak yok edebilir." sözlerinde de belirttiği gibi, örgütlerde dedikodunun işyeri morali üzerinde önemli bir etkisi vardır. Bu bağlamda, örgütlerde dedikodunun işyeri moralini etkileyeceği görüşüne dayanarak $\mathrm{H}_{1}$ hipotezi aşağıdaki gibi geliştirilmiştir:

\section{H1: Örgütlerde dedikodu, işyeri morali üzerinde negatif bir etkiye sahiptir.}

\section{3. Çalışma Eforu}

Efor literatürde anlaşılması zor ve tam olarak tanımlanamamış bir yapıdır (Macey ve Schneider, 2008: 14). Efor "bireyin kolaylıkla işlevselleştirilmiş davranışları" (Behling ve Starke, 1973: 375), "çalı̧̧ma isteği, çalı̧̧anın hareketlerinin arkasındaki güdü ya da itici güç" (Karger ve Bayha, 1987: 18) ya da "kişi-saat, kişi-ay, kişi-yıl vb. cinsinden ölçülen, işin tamamlanması için gereken insan gücü" (Trendowicz ve Jeffery, 2014: 428) olarak tanımlanmaktadır. Çalışma eforu ise "çalışmaya harcanan zamanın sonucu ve iş yoğunluğu endeksi" (Douglas, 1989: 40) ya da "işin gerçekleştirildiği güç, enerji ya da faaliyet" (Brown ve Peterson, 1994: 71) olarak tanımlanmaktadır.

Örgütlerde katkıların en üst düzeye çıkarılması çalışanların becerilerini ve enerjilerini akıllıca kullanmalarına bağlıdır (McAlister, 1995: 33). Çalışma eforu, çalışanların işlerindeki isteğe bağlı girdilerini göz önüne alarak onları yazılı hizmet akdinin ötesine taşımaktadır (Gould-Williams, 2004). Çalışma eforu fazla mesai çalışması ve çalışma yoğunluğunu içermektedir. Bunlardan birincisi, bir çalışanın normal çalışma saatlerinden fazla çalıştığı süreye karşılık gelmekteyken, ikincisi çalışma zamanı birimi başına sağlanan çaba düzeyine karşılık gelmektedir (Avgoustaki ve Frankort, 2019: 637).

Çalışma eforu insan yaşamında önemli bir unsurdur ve bir işe daha fazla çaba harcayan bireyin iyi bir performans elde etmek için daha iyi bir şansa sahip olması açısından iş performansını etkilemektedir (De Cooman vd., 2009: 302; Merino-Tejedor vd., 2015: 106). Verimliliği artırmak amacıyla çalışanlardan zihinsel ve fiziksel efor düzeylerini artırmaları istenmektedir (Hodson, 2002: 64-65). Çünkü çalı̧̧ma eforu, bir bireyin bir görevi yerine getirmek için daha fazla çaba gösterme konusundaki kasitlı istekliliğini göstermektedir, bu da çalışan performansının önemli bir belirleyicisidir (Brockner vd., 1992; Mulki vd., 2015).

Hem yöneticiler hem de çalışanlar uzun zamandır çalışanların eforu üzerinde kontrol sahibi olmak için çetin bir mücadeleye girişmişlerdir (Edwards, 1979). Yöneticiler daha entelektüel hale geldikçe ise çalışanlarını gönüllü olarak daha fazla efor göstermeye teşvik etmek için giderek daha fazla yöntem aramaya başlamışlardır (Kmec ve Gorman, 2010: 23).

Dedikodu zararsız görünebilir ancak çoğu zaman örgütlere zarar verebilmektedir (Huls, 2017). Potansiyel işten çıkarmalar, çalışma stratejileri ya da örgütün geleceği gibi konuları içeren ve bireyler hakkında olmayıp örgüt hakkında spekülasyonlarda bulunan dedikodular çalışanların örgütte olumsuz şeyler olduğunu düşünmelerine sebep olarak işe angajmanları yanı sıra çalışma eforlarının azalmasına sebep olabilmektedir (Kovary, 2017). Bununla birlikte yapılan araştırmaların sonuçları dedikodunun sadece dedikoduyu yapanlar ve dedikoduya konu olanların çalışmasını engelleyerek örgütlerde verimliliği azaltmakla kalmayıp (Career Builder, 2016), aynı zamanda işle ilgili olumsuz dedikoduya katılan çalışanların \%33'ünün örgütlerine ve çalışma arkadaşlarına karşı sinik davranışlarda bulunduğunu ortaya koymakta (Kuo vd., 2015) ve işe yönelik sinizmin ise çalışanların işi bunaltıcı, memnuniyet vermeyen ve efor harcamaya değmez olarak değerlendirdikleri bir tutum olduğunu vurgulamaktadır (Stern vd., 1990). Bu bağlamda, örgütlerde dedikodunun çalışanların çalışma eforunu etkileyeceği görüşüne dayanarak $\mathrm{H}_{2}$ hipotezi aşağıdaki gibi geliştirilmiştir:

H2: Örgütlerde dedikodu, çalışma eforu üzerinde negatif bir etkiye sahiptir.

Yapılan araştırmalar çalışanların morallerinin aynı becerilere sahip ve aynı ekipmanı kullanan çalışanların verimlilikleri arasındaki farklılıkları açıklamada çok önemli bir rolü olabileceğini ortaya koymaktadır (Goodwin vd., 2015: 204). Moralin örgütsel performansla birleştirilmesi, moral çalışma alanının ana odak 
noktalarından birini oluşturmaktadır. Morali yüksek olan örgütlerden elde edilen faydaları kısa ve öz bir şekilde özetleyen bir kelime varsa, bu da performanstır ve burada hem bireysel düzeyde hem de bir bütün olarak örgütün performansından söz edilmektedir (Bowles ve Cooper, 2009: 59-60). Moral daha fazla çalışma eforuyla doğrudan ilişkilidir, ancak çalı̧̧ma eforu ve verimlilik arasındaki ilişki moral düzeyi yükseldikçe güçlenmektedir. Bu nedenle, moralin verimlilik üzerindeki etkisinin bir kısmı, çalışanların eforlarının etkinliğini artırma meselesidir (Weakliem ve Frenkel, 2006). Yapılan araştırmalar örgütlerde moralin yüksek olmasının performans ve verimliliği artırdığını (Bowles ve Cooper, 2009), çalışanların morallerinin düşük olmasının eforlarının, iş kalitelerinin (Porath ve Pearson, 2013: 116) ve performanslarının (Patel, 2015) düşmesiyle sonuçlandığını ortaya koymaktadır. Bu bağlamda, işyeri moralinin çalışma eforunu etkileyeceği görüşüne dayanarak $\mathrm{H}_{3}$ hipotezi aşağıdaki gibi geliştirilmiştir:

\section{H3: Işsyeri morali, çalışma eforu üzerinde negatif bir etkiye sahiptir.}

Örgütlerde dedikodu huzursuz bir çalışma ortamı yaratmakta ve örgütlerde moralin düşmesine neden olmaktadır. Dedikoduyu yapanlar ve dedikoduya konu olanların çalışmasını engellemesi yanı sıra, çalışanlarda yarattığı moral bozukluğuyla da çalışanların eforlarının düşmesine yol açmaktadır. Bu bağlamda $\mathrm{H}_{4}$ hipotezi aşağıdaki gibi geliştirilmiştir:

\section{H4: İ̧̧yeri morali, örgütlerde dedikodu ve çalışma eforu arasındaki ilişkide düzenleyici etkiye sahiptir.}

\section{YÖNTEM}

\subsection{Araştırma Modeli}

Literatürde yer alan araştırmalardan yola çıkarak, açıklanan kavramlar sonucunda bu araştırmada geliştirilmiş olan teorik model Şekil 1'de gösterilmektedir.

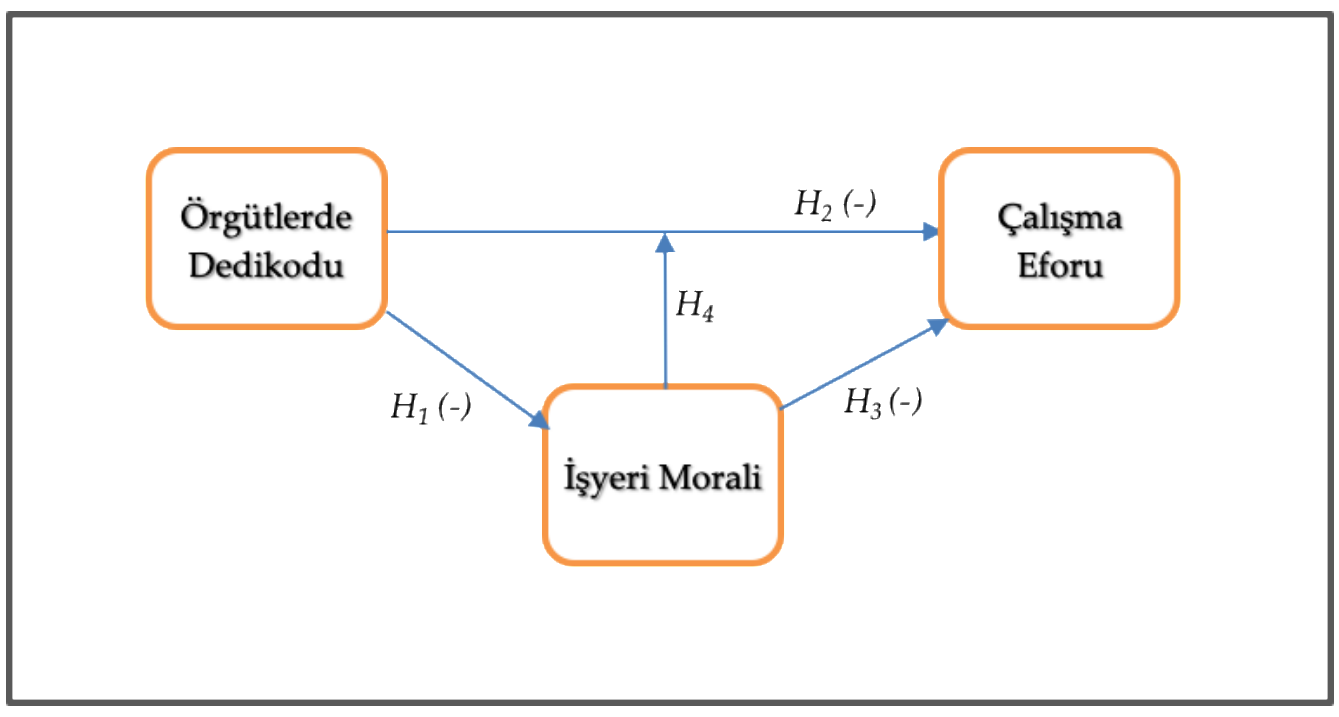

Şekil 1. Araştırma Modeli

\section{2. Örneklem}

Araştırma verileri İstanbul'da özel sektörde üretim alanında faaliyet gösteren on işletmeden kolayda örnekleme yöntemi ile toplanmıştır. Zaman kısıtı nedeniyle evrenin tamamına ulaşılamamış olup, örneklem alma yoluna gidilmiştir. Bu çalışmada $\% 95$ güvenilirlikle ve \%5'lik bir hata payıyla hesaplanan örneklem büyüklüğü en az 386 kişi olarak tespit edilmiştir (Balc1, 2007; Özdamar, 2003). Değerlendirmelerin daha gerçekçi olabilmesi bağlamında en az üç yıldır aynı işyerinde çalışanlardan gelen eksiksiz doldurulmuş 397 anket SPPS istatistik programı ile analiz edilmiştir. Örneklem bağlamında çalışanların sosyo-demografik analizi incelendiğinde; örneklemin 207'si $(\% 52,1)$ erkek ve 190'1 $(\% 47,9)$ kadındır. Cevaplayanlar yaş ortalaması $32,42(S S=8,22)$, tecrübeleri $12,74(S S=8,27)$ ve son işyerlerinde çalışma süreleri ortalaması 8,75 (SS=6,55) yıldır. \%54,9'u üniversite ve \%6,3'ü yüksek lisans mezunudur. 


\section{3. Ölçüm Araçları}

Araştırmaya ilişkin anket formunda katılımcların örgütlerde dedikodu, işyeri morali ve çalışma eforuna ilişkin algılarını belirlemek üzere 3 ayrı ölçek kullanılmıştır. Tüm anketler 5'li Likert ölçeğine göre derecelenmiştir. Anket formunda ayrıca 7 adet de demografik soru yer almaktadır.

Çalışanların örgütlerde dedikoduya yönelik algılarını belirlemek üzere Chandra ve Robinson (2010) tarafından geliştirilmiş olan 3 ifadeden oluşan ölçek kullanılmıştır. Ölçek soruları "Son altı ay içinde diğer çalışanlar işyerimde benim hakkında zarar verecek bilgiler paylaştılar" ve "Son altı ay içinde diğer çalışanlar işyerimde benim hakkımda söylentiler yaydılar" gibi ifadelerden oluşmaktadır.

Çalışanların işyeri moraline yönelik algılarını belirlemek için. Reed (2001) tarafından geliştirilmiş olan 8 ifadeden oluşan ölçek kullanılmıştır. Ölçek soruları "Çalıştı̆̆ım kurum çalışmak için iyi bir yer" ve "Yönetimin bana ve diğer çalışanlara davranış tarzından memnunum" gibi ifadelerden oluşmaktadır.

Çalışanların çalışma eforunu belirlemek için Brown ve Leigh (1996) tarafından geliştirilmiş olan 5 ifadeden oluşan ölçek kullanılmıştır. Ölçek soruları "Yapılması gereken bir iş olduğunda, tüm enerjimi bu işi yapmaya adarım" ve "İşteki tüm görevlerimde tam kapasitemle çalı̧ııorum" gibi ifadelerden oluşmaktadır.

Anket formunun oluşturulması sırasında ilk olarak ölçeklerin İngilizce formları, iyi düzeyde İngilizce bilen 4 akademisyenden oluşan bir komisyon tarafından Türkçe'ye çevrilmiş ve daha sonra bu Türkçe formlar geri tercüme edilerek Türkçe ve İngilizce formlar arasındaki tutarlılık incelenmiştir (Brislin, 1970). Daha sonra Türkçe formlar anlam ve dilbilgisi açısından incelenerek gerekli düzeltmeler yapılmış ve ölçeklerin denemelik Türkçe formları elde edilmiştir. Son olarak ölçeklerin denemelik Türkçe formları örgütsel davranış dersi alan 15 doktora öğrencisine uygulanmış ve bu öğrencilerin görüşleri doğrultusunda bazı küçük değişiklikler yapılmıştır.

\subsection{Bulgular}

Faktör yapısının ve maddelerin faktörlere göre dağılımını belirlemek için keşfedici faktör analizi (KFA) kullanılmıştır (Fabrigar vd., 1999). Keşfedici faktör analizini gerçekleştirmeden önce örneklem sayısının yeterli olup olmadığı Kaiser-Meyer- Olkin (KMO) katsayısı, maddeler arasındaki korelasyonun uygun olup olmadığını ise Barlett testi ile incelenmiştir. Veri setimiz KFA analizlerinin yapılması için Kaiser-Meyer-Olkin değerinin $0,885(>0,60)$ çok iyi olduğunu ve Barlett testinin $[\chi 2=3.396,058 ; \mathrm{df}=120 ; \mathrm{p}<0,000)]$ ise anlamlı olduğunu göstermektedir (Tabachnick ve Fidell, 2012).

Faktör sayısını belirlemek için yamaç eğiminde (scree plot) kırılma noktası kullanılırken hangi maddenin analizde kalacağına karar verirken maddelerin faktöre yükleri (item-loading) ve faktörler arası çapraz yükler (cross-loading) kullanılmıştır. Diğer bir ifade ile maddeleri analizde tutarken her bir madde yükünün $(0,60)^{\prime}$ dan yüksek olmasına ve aynı anda birden fazla faktöre yüklü maddeler var ise faktör yükleri arasındaki farkın $(0,30)^{\prime}$ dan fazla olmasına dikkat edilmiştir (Worthington ve Whittaker, 2006).

Sonuçlar yamaç eğimindeki kırılma noktasının üç faktörlü yapıya sahip olduğunu göstermiştir. Üç faktörlü yapı toplam varyansın \%65,397'sini açıklamaktadır. KFA yapı matrisine göre birinci faktör 8 maddeden oluşan işyeri morali, ikinci faktör 5 maddeden oluşan çalışma eforu ve üçüncü faktör 3 maddeden oluşan örgütsel dedikodudur. Her üç faktörün de kabul edilebilir içsel tutarlılık katsayına sahip olduğu tespit edilmiştir. Hiçbir soru analizden çıkarılmamıştır. 
E. Bilginoğlu - U. Yozgat 12/3 (2020) 2592-2610

Tablo 1. Ölçeklerin Madde Ortalamaları, Standart Sapma, Faktör Yükleri, Özdeğer, Varyans ve İçsel Tutarlılık Katsayıları

\begin{tabular}{|c|c|c|c|c|c|}
\hline Maddeler & Ort. & SS & Faktör 1 & Faktör 2 & Faktör 3 \\
\hline 8. Genel olarak işimden memnunum & 3,44 & 1,33 & 0,846 & & \\
\hline $\begin{array}{l}\text { 7. Çalıştığım koşulların güvenliği ve konforundan } \\
\text { memnunum. }\end{array}$ & 3,43 & 1,29 & 0,831 & & \\
\hline $\begin{array}{l}\text { 6. Yönetimin bana ve diğer çalışanlara davranış tarzından } \\
\text { memnunum. }\end{array}$ & 3,37 & 1,31 & 0,814 & & \\
\hline $\begin{array}{l}\text { 2. İşyerimde geleceğim konusunda kendimi güvensiz } \\
\text { hissediyorum }(\mathrm{T}) \text {. }\end{array}$ & 3,20 & 1,32 & 0,811 & & \\
\hline 4. Çalıştığım kurum çalışmak için iyi bir yer. & 3,35 & 1,33 & 0,802 & & \\
\hline 1. İşimde yaptığım şeyler için makul (adil) ücret alıyorum. & 3,22 & 1,34 & 0,774 & & \\
\hline 3. İşim çok stresli (T). & 2,93 & 1,37 & 0,755 & & \\
\hline 5. Sık sık bu işten ayrılmayı düşünüyorum (T). & 3,08 & 1,37 & 0,746 & & \\
\hline 5. Çalıştığım zaman tüm gayretimi sarf ediyorum. & 4,18 & 0,88 & & 0,774 & \\
\hline 4. İşimde başarılı olabilmek için elimden geleni yapıyorum. & 4,01 & 0,92 & & 0,739 & \\
\hline $\begin{array}{l}\text { 1. Yapılması gereken bir iş olduğunda, tüm enerjimi bu işi } \\
\text { yapmaya adarım. }\end{array}$ & 4,11 & 0,93 & & 0,721 & \\
\hline 3. İşteki tüm görevlerimde tam kapasitemle çalışıyorum. & 4,07 & 0,93 & & 0,716 & \\
\hline 2. Çalıştı̆̆ımda bunu yoğun bir şekilde yapıyorum. & 4,08 & 0,84 & & 0,715 & \\
\hline \multicolumn{6}{|l|}{$\begin{array}{l}\text { Son altı ay içinde diğer çalışanlar işyerimde benim } \\
\text { hakkında... }\end{array}$} \\
\hline 2. ... söylentiler yaydılar & 1,68 & 1,19 & & & 0,906 \\
\hline 3. ...ithamlarda/olumsuz iddialarda bulundular & 1,62 & 1,16 & & & 0,894 \\
\hline 1. ... zarar verecek bilgiler paylaştılar. & 1,65 & 1,16 & & & 0,872 \\
\hline Özdeğer & & & 5,183 & 2,823 & 2,458 \\
\hline Açıklanan Toplam Varyans & & & 32,393 & 17,645 & 15,360 \\
\hline İçsel Tutarlılık Katsayısı & & & 0,922 & 0,794 & 0,888 \\
\hline
\end{tabular}

Faktör 1: İşyeri Morali (IMM); Faktör 2: Çalışma Eforu (ÇE); Faktör 3: Örgütsel Dedikodu (ÖD); (N = 397).

Cronbach Alpha güvenilirlik katsayıları 0,794 ile 0,922 arasında değişmektedir, bu değerler çalışma değişkenlerinin güvenilir olduğunu göstermektedir (Bkz. Tablo 1). Tablo 2' de verilen korelasyon katsayıları incelendiğinde örgütsel dedikodu ile işyeri morali ve çalışma eforu arasında negatif $\left(-0,228^{* * * *} /-0,203^{* * * *}\right)$ ve işyeri morali ile çalışma eforu arasında pozitif $\left(0,191^{* * * *}\right)$ yönlü bir ilişki olduğu görülmektedir.

Tablo 2. Değişkenlerin Ortalama, Standart Sapma, Cronbach's Alpha ve Korelasyon Değerleri

\begin{tabular}{lccccc}
\hline Değişkenler & Ort. & SS & $\mathbf{1}$ & $\mathbf{2}$ & $\mathbf{3}$ \\
\hline 1 Örgütsel Dedikodu (ÖD) & 1,65 & 1,06 & $(0,89)$ & & \\
2 İşyeri Morali (İM) & 3,25 & 1,07 & $-0,228^{* * * *}$ & $(0,92)$ & \\
3 Çalışma Eforu (ÇE) & 4,09 & 0,67 & $-0,203^{* * * *}$ & $0,191^{* * * *}$ & $(0,79)$ \\
\hline
\end{tabular}

Not: Parantez içinde Cronbach 's Alpha değerleri verilmiştir; ${ }^{*} \mathrm{p}<0.05,{ }^{* *} \mathrm{p}<0.01,{ }^{* * * *} \mathrm{p}<0.001 ; \mathrm{N}=397$.

İşyeri moralinin örgütsel dedikodu ile çalışma eforu arasındaki düzenleyici etkisini test etmek için hiyerarşik regresyon analizi kullanılmış ilk olarak

(i) örgütsel dedikodunun işyeri morali üzerindeki etkisi irdelenmiştir,

daha sonra işyeri moralinin örgütsel dedikodu ile çalışma eforu arasındaki ilişki üzerindeki düzenleyici etkisini araştırmak için Aiken ve West (1991) süreci takip edilerek

(ii) örgütsel dedikodunun çalışma eforuna etkisi,

(iii) işyeri moralinin çalışma eforuna etkisi, 
E. Bilginoğlu - U. Yozgat 12/3 (2020) 2592-2610

(iv) örgütsel dedikodu ve işyeri moralinin çalışma eforuna etkisi,

(v) örgütsel dedikodu, işyeri morali ve örgütsel dedikodu ile işyeri moralinin çarpımının çalışma eforuna etkisi irdelenmiştir.

Hiyerarşik regresyon analizi sonuçları Tablo 3'te verilmiştir.

Tablo 3. Regresyon Analizi Sonuçları

\begin{tabular}{llccccccc}
\hline & & Std. Beta & t-değeri & F-değeri & $\mathbf{R}^{2}$ & Tolerans & VIF & Hipotez \\
\hline (i) & ÖD $\rightarrow$ IM & $-0,228^{* * *}$ & $-4,663$ & 21,744 & 0,050 & 1,000 & 1,000 & $\mathrm{H}_{1} \checkmark$ \\
\hline (ii) & ÖD $\rightarrow$ ÇE & $-0,203^{* * *}$ & $-4,120$ & 16,971 & 0,039 & 1,000 & 1,000 & $\mathrm{H}_{2} \checkmark$ \\
\hline (iii) & İM $\rightarrow$ ÇE & $0,191^{* * *}$ & 3,873 & 15,000 & 0,034 & 1,000 & 1,000 & $\mathrm{H}_{3} \checkmark$ \\
\hline \multirow{2}{*}{ (iv) } & ÖD $\rightarrow$ ÇE & $-0.168^{* *}$ & $-3,355$ & \multirow{2}{*}{9,320} & 0,059 & 0,948 & 1,055 & \\
& İM $\rightarrow$ ÇE & $0,153^{* *}$ & 3,053 & & & & & \\
\hline \multirow{2}{*}{ (v) } & ÖD $\rightarrow$ ÇE & $-0,263^{* * *}$ & $-4,962$ & & & 0,661 & 1,514 & \\
& İ $\rightarrow$ ÇE & $0,175^{* * *}$ & 3,526 & \multirow{2}{*}{12,435} & 0,090 & 0,935 & 1,069 & $\mathrm{H}_{4} \checkmark$ \\
& ÖDxİM $\rightarrow$ ÇE & $0,226^{* * *}$ & 3,837 & & & 0,662 & 1,510 & \\
\hline
\end{tabular}

(i) Örgütsel dedikodu iş moralini negatif etkilemektedir (Std. $\beta=-0,228, p<0,001)$. Hipotez 1 kabul edilmiştir.

(ii) Örgütsel dedikodu çalışma eforunu negatif etkilemektedir (Std. $\beta=-0,203, p<0,001$ ). Hipotez 2 kabul edilmiştir.

(iii) İşyeri morali çalışma eforunu pozitif etkilemektedir (Std. $\beta=0,191, \mathrm{p}<0,001$ ). Hipotez 3 kabul edilmiştir.

(iv) Örgütsel dedikodu çalışma eforunu negatif (Std. $\beta=-0,168, p<0,01$ ) ve işyeri morali çalışma eforunu pozitif etkilemektedir (Std. $\beta=0,153, \mathrm{p}<0,01)$.

(v) Örgütsel dedikodu ile işyeri moralinin çarpımının etkisi istatiksel olarak anlamlıdır $($ Std. $\beta=0,226$, $\mathrm{p}<0,001)$. Hipotez 4 kabul edilmiştir.

İşyeri moralinin düzenleyici etkisini görselleştirmek için değişkenin ortalama değerinin bir standart sapma üstü ve altındaki değerlerine bağlı değişim Şekil 2'de gösterilmiştir. (Aiken ve West, 1991).

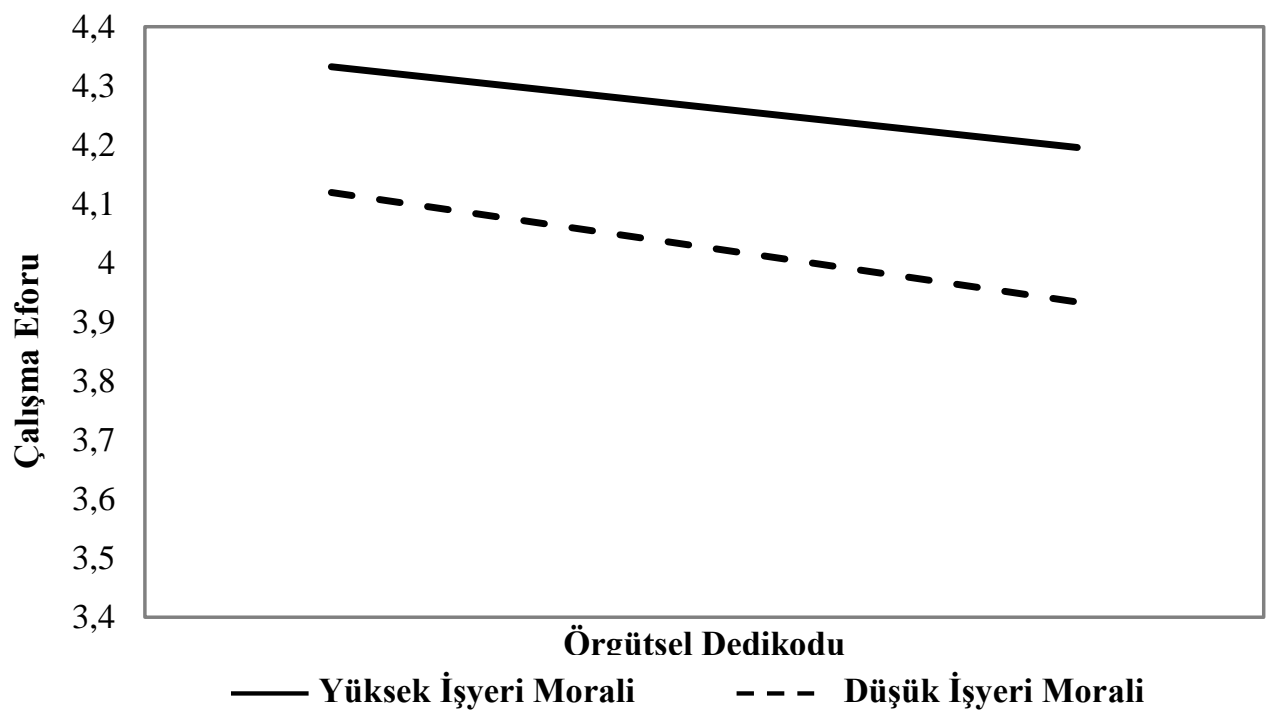

Şekil.2. İşyeri Moralinin Örgütsel Dedikodu Çalışma Eforu İlişkisinde Düzenleyici Etkisi

Şekil incelendiğinde örgütsel dedikodunun çalışma eforunu düşürdüğü, işyeri moralleri yüksek olan çalışanların algılanan örgütsel dedikodunun her seviyesinde çalışma eforları seviyelerinin işyeri moralleri düşük olanlara göre daha yüksek olduğu görülmektedir. Ayrıca işyeri moralleri yüksek çalışanların çalışma eforlarının düşük olanlara göre daha az etkilendikleri tespit edilmiştir. 


\section{SONUÇ VE TARTIŞMA}

Örgütlerde çalışanlar arasında başkalarının özel hayatlarını ya da örgütün işlerini müzakere etmek arzusu tarafından motive edilen bir tartışma olan dedikodu (Furnham ve Taylor, 2011: 88) çalışanlar arasında vazgeçilmez bir davranıştır (Kim vd., 2019: 30).

Örneklem bağlamında araştırma sonuçları örgütlerde dedikodunun işyeri morali üzerinde negatif etkisi olduğunu ortaya koymaktadır. Bu bulgular Howard (2018), Wakeman (2013: 116), Layne (2020), Perez ve Barkhurst (2012: 198) ve Carpenter ve Fulton'ın (2010: 102) örgütlerde dedikodunun çalışan moralini düşüreceği iddialarıyla uyumludur.

Çalışan morali, çalışanların işte hissettikleri genel bakış, tutum, tatmin ve güveni tanımlamaktadır. Çalışanlar çalışma ortamları hakkında olumlu hissettikleri ve orada en önemli kariyer ve mesleki ihtiyaçlarını karşılayabileceklerine inandıklarında, işyeri morali yüksek olmaktadır. Çalışma ortamının ana bileşenleri

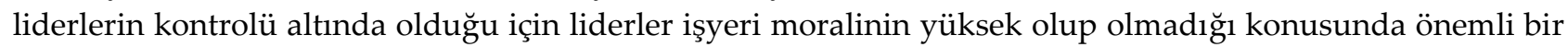
role sahiptirler (Gilberg, 1992; Heathfield, 2019). Günümüzde liderler, örgütlerinde sürekli olarak çalışanların morallerini yüksek tutmak için ellerinden geleni yapmalıdırlar. Çünkü günümüzde çalışanlar motivasyon ve ilham alma konuları üzerinde önemle durmakta ve bir aidiyet duygusu ya da bir amaç gibi inanacak bir şeye daha da önemlisi umuda ihtiyaçları olduğunu vurgulamaktadırlar (Bruce, 2003: ix). İşyerinde moral yüksek olmadığında, kişiler başarılı olmak konusunda motivasyona sahip olmayacaklar ve bununla birlikte verimli ya da yaratıcı olmak için çaba göstermeyerek örgütün geleceğine dair kayıtsız kalacaklardır (Root, 2020). Yapılan bir araştırmanın sonuçları dedikodunun en uygunsuz işyeri davranışı olduğunu ortaya koymaktadır (Kurtzleben, 2018). Dedikodu aynı zamanda çağdaş işyerleri bağlamında bir istismar aracı olarak nitelendirilmiştir (Davenport vd., 1999). Örgütlerde dedikodu çalışanların kaygı duymasına yol açabileceği ve çalışanlara ya da örgütün itibarına zarar verme potansiyeline sahip olduğu için liderlerin hızlı bir şekilde ilgilenmeleri ve kontrol altına almaları gereken bir konudur. Liderler örgütlerde dedikoduya asla tolerans gösterilmeyeceğine dair politikaları yürürlüğe koymalı ve çalışanlara kötü niyetli kişisel dedikoduların kabul edilemez olduğu konusunda bilgi vermelidirler. Yöneticiler çalışanlardan biri tarafından tehlikeli, kasıtlı söylentiler yayıldığına dair bir duyum aldıkları zaman, bu durumun verdiği zararı tespit etmek ve durumu düzeltmek için doğrudan ilgili kişilerle bir araya gelerek dedikodunun kaynağ tespit etmeli ve sonrasında da bu kişilerle yüzleşmelidirler (Burke ve Wise, 2003: 74; Schwantes, 2017). Birçok kurumun çalışan el kitaplarında dedikodu yapılmasını kısıtlayan resmi politikaları yer almaktadır (Wilkie, 2020). Bununla birlikte dedikodu yaparak işyerinde huzurun kaçırılması ve işin yapılmasını engelleyici ortam oluşturulması tazminatsız işten çıkarılmaya sebep olabilmektedir (Erdem, 2019; O'Callaghan ve Hartigan, 2015). Ancak yapılan çalışmaların sonuçları çoğu kişinin dedikodu yaptığını ortaya koymakta ve dedikodunun her yerde olduğu fikrini desteklemektedir. Dedikodunun bu denli yaygın olması, dedikodulara karşı yaptırımların boşuna olabileceğini düşündürmektedir (Robbins ve Karan, 2020: 193).

Örgütlerde dedikodunun önüne geçilmesi için çalışanlara da görev düşmektedir. Örgütte dedikodu yapıldığına tanık olsalar bile dedikoduyu yapan kişiyi duymazdan gelerek ve yapılan dedikoduya sözlü ya da sözsüz olarak katılmayarak, dedikodunun kaynağını caydırmaları, dedikodu yapmanın artık eğlenceli olmaktan çıkmasıyla sonuçlanacaktır (Baker ve Jones, 1996: 85; Lucas, 2018; Schwantes, 2017). Sadece bir dedikoduyu dinlemek bile bu konuda suç ortağı olmak anlamına gelmektedir. Olumsuz dedikoduları bastırmak öz disiplin gerektirir ve kişilerin dedikodu ve dedikoducuya karşı tavır almak konusunda istekli olmasi gerekmektedir (Therrien, 2004).

Araştırma sonuçları örgütlerde dedikodunun çalışma eforu üzerinde negatif etkisi olduğunu da ortaya koymaktadır. Bu bulgular Howard'ın (2018) örgütlerde dedikodunun verimliliği düşüreceği iddialarıyla uyumlu, Dores Cruz vd. (2019)'nin olumsuz dedikodunun hedefi olan kişilerin dedikodu doğru olduğu zaman kısa vadede çalışma eforlarını artırdıklarına dair çalışma bulguları ve Alshehre'nin (2017: 127) örgütlerde dedikodudan doğan çalışanlar arası etkileşimin çalışma sürecinin daha hızlı ilerlemesine yardımcı olarak çalışanların çalışma eforlarını artırdığına dair iddiaları ile ise uyumsuzdur.

Günümüzün rekabetçi, istikrarsız ve hızla değişen iş ortamında, tüm ürünler zaman içinde potansiyel olarak kopyalanabilir oldukları için örgütlerin benzersiz fonksiyonel özelliklere sahip mükemmel ürünlerle kendilerini farklılaştırmaları giderek zorlaşmaktadır (Charan, 2010: 24). Örgütler için rekabet avantajının kaynağı artık teknoloji, ürünler ve patentler değil, en önemli varlık ve farklılaştırıcıları olarak görülen 
çalışanlarının yönetilmesidir (Bakker ve Schaufeli, 2008: 147; Charan, 2010: 24; Pfeffer, 1994: 4). Bu nedenle, örgütler yüksek motivasyonlu ve çalışkan bir işgücüne her zamankinden daha fazla bağımlı hale gelmişler ve çalışma eforu kavramına kurumsal ve akademik ilgi artmıştır (Dysvik ve Kuvaas, 2013: 412; Steers vd., 2004: 383-384). Yüksek çalışma eforu performans ve iş tatmini gibi verimliliğin artmasına neden olan olumlu sonuçlarla bağlantılı olduğu için örgütler için önemlidir (Brown ve Peterson, 1994: 75-76; Dysvik vd., 2014: 729; Fisher ve Noble, 2004: 159; Hofmans vd., 2014, p. 693).

Çalışma eforu, bir bireyin işteki verimli davranış konusunda onu motive eden tüm bilişsel özelliklerini kapsayan tutum ve inançların bir sonucudur (Ruch, 1994: 113). Çalışma eforu, üretim sürecinin karmaşık doğası nedeniyle yüksek verimliliği garanti etmek için özel görevler tahsis etmeyi imkânsız kılan önemli bir değişken haline gelmektedir. Yani, yöneticiler çalışanlara ne yapacaklarını ve nasıl yapacaklarını söyleyerek yüksek verimlilik elde edemezler. Üretim süreci karmaşık ve kendine özgüdür. Çalışanlar işlerinde bağımsızdırlar ve çalışma eforu verimli ile daha az verimli çalışanları birbirinden ayırmaktadır (Ros, 2001: 53). Örgütler, çalışanlarca daha fazla çalışma eforu sergilenmesini motive eden koşullar yaratarak verimlilik artışına katkıda bulunmalıdırlar (Kaufman, 2008: 37). Büyüme, yaşam standartları ve açığın azaltılması konusundaki tartışmalar verimlilik ve verimliliğin artırılması noktasında bir araya geldikleri için verimlilik ve verimlilik artışı hem politik bir zorunluluk hem de bir iş gerekliliğini oluşturmaktadır (Price Waterhouse Coopers, 2014). Çalışanlar sık sık bir araya gelerek bir diğer çalışan ya da örgüt hakkında fısıldaşarak zaman harcıyorlarsa, bu açıkça çalışmadıkları anlamına gelmektedir. İster bir araya gelerek yüz yüze, ister e-posta ya da mesajlaşma yoluyla yapılsın, örgütlerde dedikodu ciddi bir şekilde verimliliği azaltmaktadır. En basit değerlendirmeyle, dedikodu yapan kişi çalışmıyor demektir ve bu da verimlilik kaybıyla sonuçlanmaktadır (West Virginia Employment Law Letter, 2008). Bu araştırma işyeri moralinin örgütlerde dedikodu ve çalışma eforu arasındaki ilişkide düzenleyici etkisi olduğuna dair bulguları ile literatüre katkıda bulunmaktadır.

Geçmiş yıllardan farklı olarak, dedikodular artık çalışanların çay ya da kahve aldıkları sırada ettikleri sohbetlerle sınırlı kalmamaktadır. Günümüzde sosyal medya, mesajlaşma, uygulamalar ve diğer modern iletişim biçimleri sayesinde, dedikodular eskisine göre çok daha geniş bir etkiyle sayısız şekilde yayılabilmektedir. Bu yüzden de örgütlerde dedikodu günümüzde daha önce hiç olmadığı kadar büyük bir problem oluşturmaktadır (Janove, 2019). Ancak ne yazık ki dedikodu hayatın bir parçasıdır. Ne yöneticiler ne de insan kaynakları departmanı örgütlerde dedikoduyu tamamen ortadan kaldıramasa da örgüt içinde sağlam iletişim kanallarını kullanarak, çalışanlara dedikodunun potansiyel zararlarına dair eğitimler vererek ve dedikodu konusunda yaptırımlar içeren örgüt politikaları uygulayarak örgütte dedikoduyu yapan ve yayan kişilerin kontrol altına alınması ve engellenmesi adına adımlar atılabilmektedir.

Her bilimsel araştırmada söz konusu olan kısıtlar bu araştırmada da söz konusudur. Bu açıdan araştırma kapsamı yalnızca özel sektör çalışanları ile sınırlı tutulmuştur. Her ne kadar özel sektörün doğası gereği kamu sektöründen daha verimli olduğu iddiası hiçbir zaman tam olarak netleştirilememiş olsa da (UNDP Global Centre for Public Service Excellence, 2015: 3), son yıllarda özel sektör dinamizmine karşı kamu sektörü verimliliği baskın bir politik anlatıyı oluşturmaktadır (Simms, 2013). Bu açıdan araştırmanın kamu sektöründe çalışan bireyler üzerinde tekrarlanması bu konu hakkında daha geniş fikir sahibi olma noktasında oldukça yararlı olacaktır. Bundan sonra yapılacak olan araştırmalarda bu hususların ele alınıp incelenmesinin alana katkı sağlayacağı düşünülmektedir.

Örgütlerde dedikodu toksik bir çalışma ortamı yaratmaktadır. Ancak örgütlerde doğru bir iletişim yöntemi kullanılarak yapılan eleştiriler gerekli ve sağlıklı olabilmektedirler. Eleştiri, işyeri moralini düşürmeyeceği gibi verimliliğin korunması ve geliştirilmesine yardımcı olabilecektir (Lovering, 2020). Daha sonra yapılacak olan araştırmalarda örgütlerde eleştirinin işyeri morali ve çalışma eforu üzerindeki etkilerinin ele alınıp incelenmesinin literatüre katkı sağlama açısından anlamlı olacağı düşünülmektedir. 


\section{KAYNAKLAR}

Aiken, L.S., West, S.G. (1991). Multiple Regression: Testing and Interpreting Interactions. Newbury Park: Sage Publications.

Akande, A., Odewale, F. (1994). One More Time - How to Stop Company Rumours, Leadership and Organization Development Journal, 15(4), 27-30.

Ali, V. (2013, June 25). The High Cost of Low Morale - and What To Do About It. https://www.barrettrose.com/the-high-cost-of-low-morale-and-what-to-do-about-it/ adresinden alınmıştır. [Erişim Tarihi 29.02.2020]

Alshehre, R.A.M. (2017) Positive Effects of Gossiping at Work, Open Journal of Medical Psychology, 6, 126-132.

Avgoustaki, A., Frankort, H.T.W. (2019). Implications of Work Effort and Discretion for Employee Well-Being and Career-Related Outcomes: An Integrative Assessment, ILR Review, 72(3), 636-661.

Babalola, M.T., Ren, S., Kobinah, T., Qu, Y.E., Garba, O.A., Guo, L. (2019). Negative Workplace Gossip: Its Impact on Customer Service Performance and Moderating Roles of Trait Mindfulness and Forgiveness, International Journal of Hospitality Management, 80, 136-143.

Baker, J.S., Jones, M.A. (1996). The Poison Grapevine: How Destructive are Gossip and Rumor in the Workplace, Human Resource Development Quarterly, 7, 75-86.

Bakker, A.B., Schaufeli, W.B. (2008). Positive Organizational Behavior: Engaged Employees in Flourishing Organizations, Journal of Organizational Behavior, 29(2), 147-154.

Balcı, A. (2007). Sosyal Bilimlerde Araştırma Yöntem, Teknik ve Illkeler. Ankara: Pegem Akademi Yayıncılık.

Bassuk, A., Lew, C. (2016, November 11). The Antidote to Office Gossip, Harvard Business Review, 2-4.

Baumeister, R.F., Zhang, L., Vohs, K.D. (2004). Gossip as Cultural Learning, Review of General Psychology, 8(2), $111-121$.

Beersma, B., Van Kleef, G.A. (2012). Why People Gossip: An Empirical Analysis of Social Motives, Antecedents, and Consequences, Journal of Applied Social Psychology, 42(11), 2640-2670.

Behling, O. Starke, E.S. (1973). The Postulates of Expectancy Theory, Academy of Management Journal, 16, 373388.

Bencsik, A., Juhasz, T., Mura, L., Csanadi, A. (2019). Impact of Informal Knowledge Sharing for Organizational Operation, Entrepreneurial Business and Economics Review, 7(3), 25-42.

Ben-Hador, B. (2019). Social Capital Levels, Gossip and Employee Performance in Aviation and Shipping Companies in Israel, International Journal of Manpower, 40(6), 1036-1055.

Ben-Ze'ev, A. (2000). The Subtlety of Emotions. Cambridge: MIT Press.

Bergmann, J.R. (1993). Discreet Indiscretions: The Social Organization of Gossip. New York: Aldine de Gruyter.

Better Buys (2017). Employees Behaving Badly: What's Really Happening at The Office? https://www.betterbuys.com/employees-behaving-badly/ adresinden alınmıştır. [Erişim Tarihi 15.01.2020]

Bewley, T. F. (1999). Why Wages don't Fall in a Recession. Cambridge, MA: Harvard University Press.

Bonner, J.M. (2016). Biting the Hand that Feeds You: Employees' Reactions to their Own Gossip about Highly (Un)supportive Supervisors. Graduate College of the Oklahoma State University Yayınlanmamış Doktora Tezi.

Bowden, O. (2019, December 11). Workplace Gossip Happens Every Day: Here's How to Keep it Positive. https://globalnews.ca/news/6282889/dealing-with-workplace-gossip/ adresinden alınmıştır. [Erişim Tarihi 15.01.2020]

Bowles, D., Cooper, C. (2009). Employee Morale: Driving Performance in Challenging Times. New York: Palgrave Macmillan. 
E. Bilginoğlu - U. Yozgat 12/3 (2020) 2592-2610

Boyne, G.A. (2002). Public and Private Management: What's The Difference? Journal of Management Studies, 39(1), 97-122.

Brady, D.L., Brown, D.J., Liang, L.H. (2017). Moving Beyond Assumptions of Deviance: The Reconceptualization and Measurement of Workplace Gossip, Journal of Applied Psychology, 102(1), 125.

Brislin, R. W. (1970). Back-Translation for Cross-Cultural Research, Journal of Cross Cultural Psychology, 1(3), 185-216.

Brockner, J., Grover, S., Reed, T., Dewitt, R. (1992). Layoffs, Job Insecurity, and Survivors' Work Effort: Evidence of an Inverted-U Relationship, Academy of Management Journal, 35, 413-425.

Brown, S.P., Leigh, T.W. (1996). A New Look at Psychological Climate and Its Relationship to Job Involvement, Effort, and Performance, Journal of Applied Psychology, 81(4), 358-368.

Brown, S.P., Peterson, R.A. (1994). The Effect of Effort on Sales Performance and Job Satisfaction, Journal of Marketing, 58, 70-80.

Bruce, A. (2003). Building a High Morale Workplace. New York: McGraw-Hill.

Burke, L.A., Wise, J.M. (2003). The Effective Care, Handling and Pruning of the Office Grapevine, Business Horizons, 46(3), 71-76.

Campbell, S. (2016, July 21). The 6 Toxic Traits of Workplace Gossips. https://www.entrepreneur.com/article/279445 adresinden alınmıştır. [Erişim Tarihi 15.01.2020]

Carpenter, M.J., Fulton, R. (2010). Law Enforcement Management: What Works and What Doesn't! New York: Looseleaf Law Publications.

Career Builder (2016, June 09). New CareerBuilder Survey Reveals How Much Smartphones Are Sapping Productivity at Work. https://www.careerbuilder.ca/share/aboutus/pressreleasesdetail.aspx?sd=6\%2F9\%2F2016veid=pr954 veed $=12 \% 2 F 31 \% 2 F 2016$ adresinden alınmıştır. [Erişim Tarihi 29.02.2020]

Chandra, G., Robinson, S.L. (2010). They're Talking about me Again: The Impact of Being the Target of Gossip on Emotional Distress and Withdrawal, Paper Presented at the Annual Meeting of the Academy of Management.

Charan, R. (2010). Banking on Talent, People Management, 24-25.

Chulguen, Y., Minjock, R., Voss, B., Colarelli, S.M. (2014). Gossip in Organizations: From an Evolutionary Psychological Perspective, Academy of Management Annual Meeting Proceedings, 2014(1), 631-636.

CMA Competition \& Market Authority (2015). Productivity and Competition: A Summary of The Evidence.https://assets.publishing.service.gov.uk/government/uploads/system/uploads/attachment_ data/file/443448/Productivity_and_competition_report.pdf [Erişim Tarihi 15.01.2020]

Coady, C.A.J. (2006). Pathologies of Testimony. J. Lackey ve E. Sosa (Ed.) The Epistemology of Testimony içinde (253-271). Oxford: Oxford University Press.

Cohen, S., Eimicke, W., Heikkila, T. (2013). The Effective Public Manager: Achieving Success in Government Organizations. San Francisco, CA: John Wiley \& Sons.

Craig, W. (2017, August 29). How Positive Employee Morale Benefits Your Business. https://www.forbes.com/sites/williamcraig/2017/08/29/how-positive-employee-morale-benefitsyour-business/\#6ba788712549 adresinden alınmıştır. [Erişim Tarihi 15.01.2020]

Dores Cruz, T.D., Beersma, B., Dijkstra, M.T.M., Bechtoldt, M.N. (2019). The Bright and Dark Side of Gossip for Cooperation in Groups, Frontiers in Psychology, 10, 1374.

Davenport, N., Schwartz, R.D., Elliott, G.P. (1999). Mobbing: Emotional Abuse in the American Workplace. Ames, Iowa: Civil Society. 
E. Bilginoğlu - U. Yozgat 12/3 (2020) 2592-2610

Deal, T.E., Kennedy, A.A. (1982). Corporate Cultures: The Rites and Rituals of Corporate Life. USA: AddisonWesley Publishing Company.

De Cooman, R., De Gieter, S., Pepermans, R., Jegers, M. (2009). A Cross-Sector Comparison of MotivationRelated Concepts in For-Profit and Not-For-Profit Service Organizations, Nonprofit and Voluntary Sector Quarterly, 40, 296-317.

Douglas, E. J. (1989). The Simple Analytics of the Principal-Agent Incentive Contract, Journal of Economic Education, Winter, 39-51.

Dunbar, R.I.M. (2004). Gossip in Evolutionary Perspective, Review of General Psychology, 8(2), 100-110.

Dunbar, R.I.M., Marriott, A., Duncan, N.D.C. (1997). Human Conversational Behavior, Human Nature, 8(3), 231-246.

Dysvik, A., Kuvaas, B. (2013). Intrinsic and Extrinsic Motivation as Predictors of Work Effort: The Moderating Role of Achievement Goals, British Journal of Social Psychology, 52(3), 412-430.

Dysvik, A., Kuvaas, B., Buch, R. (2014). Perceived Training Intensity and Work Effort: The Moderating Role of Perceived Supervisor Support, European Journal of Work and Organizational Psychology, 23(5), 729-738.

Edwards, R. (1979). Contested Terrain: The Transformation of the Workplace in the Twentieth Century. New York: Basic.

Emler, N. (1994). Gossip, Reputation, and Social Adaptation. R. F. Goodman ve A. Ben-Ze'ev (Ed.) Good Gossip içinde (119-140). Lawrence, KS: University Press of Kansas.

Erdem, F. (2019, Mart 25). Dedikodu Yapan Yandı! Tazminatsız Atılabilirsiniz... https://www.sabah.com.tr/memurlar/haberler/2019/03/25/dedikodu-yapan-yandi-tazminatsizatilabilirsiniz adresinden alınmıştır. [Erişim Tarihi 05.03.2020]

Erdogan, B., Bauer, T.N., Walter, J. (2015). Deeds that Help and Words that Hurt: Helping and Gossip as Moderators of the Relationship Between Leader-Member Exchange and Advice Network Centrality, Personnel Psychology, 68(1), 185-214.

Fabrigar, L.R., Wegener, D.T., MacCallum, R.C., Strahan, E.J. (1999). Evaluating The Use of Exploratory Factor Analysis in Psychological Research, Psychological Methods, 4(3), 272-299.

Farley, S.D. (2011). Is Gossip Power? The Inverse Relatonships between Gossip, Power and Likeability, European Journal of Social Psychology, 41(5), 574- 579.

Farley, S.D., Timme, D.R., Hart, J.W. (2010). On Coffee Talk and Break-Room Chatter: Perceptions of Women Who Gossip in the Workplace, The Journal of Social Psychology, 150(4), 361-368.

Fisher, C. D., Noble, C. S. (2004). A Within-Person Examination of Correlates of Performance and Emotions While Working, Human Performance, 17(2), 145-168.

Foster, E.K. (2004). Research on Gossip: Taxonomy, Methods, and Future Directions, Review of General Psychology, 8, 78-99.

Furnham, A., Taylor, J. (2011). Bad Apples Identify, Prevent \& Manage Negative Behavior at Work. UK: Palgrave Macmillan.

Gabriel, Y. (1995). The Unmanaged Organization: Stories, Fantasies and Subjectivity, Organization Studies, 16(3), 477-501.

Gartenstein, D. (2020). Signs of a Competitive Workplace. https://work.chron.com/signs-competitiveworkplace-2543.html adresinden alınmıştır. [Erişim Tarihi 05.03.2020]

Giardini, F., Wittek, R. (2019). Gossip, Reputation and Sustainable Reputation. F. Giardini ve R. Wittek (Ed.). The Oxford Handbook of Gossip and Reputation içinde (23-46). New York: Oxford University Press.

Gilberg, K. (1992). Trained Supervisors can Enhance Workplace Morale and Performance, Supervision, 53(12), 14. 
E. Bilginoğlu - U. Yozgat 12/3 (2020) 2592-2610

Goodwin, N., Harris, J., Nelson, J.A., Roach, B., Torras, M. (2015). Microeconomics in Context. New York: Routledge.

Gould-Williams, J. (2004). The Effects of 'High Commitment' HRM Practices on Employee Attitude: The Views of Public Sector Workers, Public Administration, 82(1), 63-81.

Grosser, T.J., Lopez-Kidwell, V., Labianca, G. (2010). A Social Network Analysis of Positive and Negative Gossip in Organizational Life, Group ve Organization Management, 35, 177-212.

Heathfield, S.M. (2019, November 27). You Can Boost Employee Morale: Simple Ideas for Improving Morale in Your Workplace. https://www.thebalancecareers.com/you-can-boost-employee-morale-1918107 adresinden alınmıştır. [Erişim Tarihi 05.03.2020]

Hodson, R. (2002). Management Citizenship Behavior and its Consequences, Work and Occupations, 29, 64-96.

Hofmans, J., Gelens, J., Theuns, P. (2014). Enjoyment as a Mediator in the Relationship between Task Characteristics and Work Effort: An Experience Sampling Study, European Journal of Work and Organizational Psychology, 23(5), 693-705.

Howard, E. (2018, September 27). Can Workplace Gossip Be Eliminated? https://www.employmentlawhandbook.com/employee-handbooks/can-workplace-gossip-beeliminated/ adresinden alınmıştır. [Erişim Tarihi 05.03.2020]

Huls, A. (2017, March 10). What to Do About an Employee Who Won't Stop Gossiping? https://sba.thehartford.com/managing-employees/employee-gossip/ adresinden alınmıştır. [Erişim Tarihi 29.02.2020]

Janove, J. (2019, December 05). How HR and Management Can Help Eradicate Workplace Gossip. https://www.shrm.org/resourcesandtools/hr-topics/employee-relations/humanity-into$\mathrm{hr} /$ pages/eradicating-workplace-gossip.aspx adresinden alınmıştır. [Erişim Tarihi 15.01.2020]

Jones, E., Haenfler, R., Johnson, B. (2007). The Better World Handbook: Small Changes That Make A Big Difference. Canada: New Society Publishers.

Karger, D.W., Bayha, F.H. (1987). Engineered Work Measurement: The Principles, Techniques, and Data of MethodsTime Measurement, Background and Foundations Work Measurement and Methods-Time Measurement, Plus Other Related Material. New York: Industrial Press Inc.

Kaufman, B.E. (2008). What Unions Do: Insights from Economic Theory. J. T. Bennett ve B. E. Kaufman (Ed.) What Do Unions Do? A Twenty-Year Perspective içinde (12-45). New Jersey: Transaction Publishers.

Kendrick, K.D. (2017) The Low Morale Experience of Academic Librarians: A Phenomenological Study, Journal of Library Administration, 57(8), 846-878.

Kennedy, A. (2014, June 20). A Point of View: Why Gossip has to Stop. https://www.bbc.com/news/magazine27883308 adresinden alınmıştır. [Erişim Tarihi 15.01.2020]

Kırılmaz, H. (2011). Kamu Kurumlarında Performans Yönetimi Uygulamaları, Sağglk Düşüncesi ve Tıp Kültürü Dergisi, 19.

Kim, A., Moon, J., Shin, J. (2019). Justice Perceptions, Perceived Insider Status, and Gossip at Work: A Social Exchange Perspective, Journal of Business Research, 97, 30-42

Kmec, J.A., Gorman, E.H., (2010). Gender and Discretionary Work Effort: Evidence From the United States and Britain, Work and Occupations, 37(1), 3-36.

Kniffin, K.M., Wilson, D.S. (2010). Evolutionary Perspectives on Workplace Gossip: Why and How Gossip Can Serve Groups, Group ve Organization Management, 35(2), 150-176.

Kovary, G. (2017, May 19). Workplace Gossip and How It Affects Engagement. https://www.ngenperformance.com/blog/leadership-2/workplace-gossip-and-how-it-affectsengagement adresinden alınmıştır. [Erişim Tarihi 29.02.2020] 
E. Bilginoğlu - U. Yozgat 12/3 (2020) 2592-2610

Kuo, C., Chang, K., Quinton, S., Lu, C., Lee, I. (2015). Gossip in The Workplace and The Implications for HR Management: A Study of Gossip and its Relationship to Employee Cynicism, The International Journal of Human Resource Management, 26(18), 2288-2307.

Kurland, N.B., Pelled, L.H. (2000). Passing the Word: Toward a Model of Gossip and Power in the Workplace, Academy of Management Review, 25(2), 428-438.

Kurtzleben, D. (2018, February 23). POLL: The 'Inappropriate' Office Behaviors Most Pervasive In Workplaces. https://www.npr.org/2018/02/23/586174752/poll-the-inappropriate-office-behaviors-most-pervasivein-workplaces adresinden alınmıştır. [Erişim Tarihi 05.03.2020]

Lanz, H. (1936). Metaphysics of Gossip, International Journal of Ethics, 46(4), 492-499.

Layne, E. (2020). The Damage of Gossip in the Workplace. https://smallbusiness.chron.com/damage-gossipworkplace-15218.html adresinden alınmıştır. [Erişim Tarihi 15.01.2020]

Litman, J.A., Pezzo, M.V. (2005). Individual Differences in Attitudes Towards Gossip, Personality and Individual Differences, 38(4), 963-980.

Liu, X., Kwan, H.K., Zhang, X. (2018, August). Introverts Maintain Creativity: A Resource Depletion Model of Negative Workplace Gossip, Asia Pacific Journal of Management, 1-20.

Lovering, C. (2020). Does Workplace Gossip ve Criticism Lead to Low Productivity? https://smallbusiness.chron.com/workplace-gossip-criticism-lead-low-productivity-30992.html adresinden alınmıştır. [Erişim Tarihi 15.01.2020]

Lucas, S. (2018, May 16). 97\% of People Say This is the Most Toxic Team Behavior. https://gusto.com/blog/people-management/work-gossip adresinden alınmıştır. [Erişim Tarihi 15.01.2020]

Macey, W.H., Schneider, B. (2008). The Meaning of Employee Engagement, Industrial and Organizational Psychology, 1, 3-30.

Maguen, S., Litz, B.T. (2006). Predictors of Morale in U.S. Peacekeepers, Journal of Applied Social Psychology, $36(4), 820-836$.

Manning, F.J. (1991). Morale, Cohesion, and Esprit de Corps. R. Gal ve A. D. Mangelsdorff (Ed.) Handbook of Military Psychology içinde (453-470). Chichester, UK: Wiley.

Matteson, S. (2008). The Secret Master Key To Losing Weight (And Keeping It Off Forever). USA: Shannon Matteson.

McAlister, D.J. (1995). Affect- and Cognition-Based Trust Formations for Interpersonal Cooperation in Organizations, Academy of Management Journal, 38(1), 24-59.

McAndrew, F.T. (2019). Gossip as a Social Skill. F. Giardini ve R. Wittek (Ed.) The Oxford Handbook of Gossip and Reputation içinde (173-192). New York: Oxford University Press.

McKinsey (2006). Job Values in Today's Workforce: A Comparison of Public and Private Sector Employees. https://www.mckinsey.com/ /media/mckinsey/dotcom/client_service/public\%20sector/pdfs/how_ca n_american_government_meet_its_productivity_challenge.ashx adresinden alınmıştır. [Erişim Tarini 29.02.2020]

McKinsey Center for Government (2017, April). Government Productivity: Unlocking The \$3.5 Trillion Opportunity: Executive Summary. https://www.mckinsey.com/ /media/McKinsey/Industries/Public\%20Sector/Our\%20Insights/The\%2 0opportunity\%20in\%20government\%20productivity/Executive\%20summary\%20Government\%20pr oductivity\%20unlocking\%20the\%2035\%20trillion\%20opportunity.ashx adresinden alınmıştır. [Erişim Tarini 15.01.2020]

McKnight, D.H., Ahmad, S., Schroeder, R.G. (2001). When Do Feedback, Incentive Control, And Autonomy Improve Morale? The Importance Of Employee-Management Relationship Closeness, Journal of Managerial Issues, 13(4), 466-482. 
E. Bilginoğlu - U. Yozgat 12/3 (2020) 2592-2610

McLeod, L. (2020). How to Deal With the 5 Most Negative Types of Co-workers. https://www.themuse.com/advice/how-to-deal-with-the-5-most-negative-types-of-coworkers adresinden alınmıştır. [Erişim Tarihi 15.01.2020]

Meier, K. J. (1993). Politics and The Bureaucracy: Policymaking in The Fourth Branch of Government. Belmont, CA: Wadsworth

Merino-Tejedor, E., Hontangas-Beltrán, P.M., Joan Boada-Grau, J., Lucas-Mangas, S. (2015). Hardiness as a Moderator Variable between the Big-Five Model and Work Effort, Personality and Individual Differences, $85,105-110$.

Mills, C. (2010). Experiencing Gossip: The Foundations for a Theory of Embedded Organizational Gossip, Group ve Organization Management, 35(2), 213-240.

Mitra, T., Gilbert, E. (2012.) Have you Heard? How Gossip flows through Workplace Email, AAAI International Conference on Weblogs and Social Media.

Moschandreas, M. (2000). Business Economics. London: Thomson.

Motowidlo, S.J., Borman, W.C. (1977). Behaviorally Anchored Scales for Measuring Morale in Military Units, Journal of Applied Psychology, 62(2), 177-133.

Mulki, J.P., Caemmerer, B., Heggde, G.S. (2015). Leadership Style, Salesperson's Work Effort and Job Performance: The Influence of Power Distance, Journal of Personal Selling ve Sales Management, 35(1), 322.

Noon, M., Delbridge, R. (1993). News From Behind My Hand: Gossip in Organizations, Organization Studies, 14(1), 23-36.

O'Callaghan, P., Hartigan, R. (2015). Regulation Of Worplace Gossip: Can Employers Mitigate Potential Liability Without Violating The NLRA?*,"North East Journal of Legal Studies,. 34, Article 1.

Oğuz, Ş. (2015, Kasım 10). İş Güvenceli Tembel Memur: Üretimin Keneleri 5. https://www.sabah.com.tr/yazarlar/oguz/2015/11/10/is-guvenceli-tembel-memur adresinden alınmıştır. [Erişim Tarihi 29.02.2020]

Özdamar, K. (2003). Modern Bilimsel Araştırma Yöntemleri. Eskişehir: Kaan Kitabevi.

Patel, S. (2015, August 04). 20 Creative Ways to Boost Employee Morale: Don't Lose Your Best Employees. Keep Them Happy by Implementing Ideas from This List. https://www.inc.com/sujan-patel/20creative-ways-to-boost-employee-morale.html adresinden alınmıştır. [Erişim Tarihi 29.02.2020]

Perez, D., Barkhurst, M. (2012). Paradoxes of Leadership in Police Management. USA: Cengage Learning.

Pfeffer, J. (1994). Competitive Advantage Through People: Unleashing the Power of the Work Force. Boston: Harvard Business School Press.

Porath, C., Pearson, C. (2013, January-February). The Price of Incivility, Harvard Business Review, 114-121.

Price Waterhouse Coopers (2014). Productivity in The Public Sector: What Makes a Good Job? https://www.pwc.com/gx/en/psrc/united-kingdom/assets/pwc-productivity-in-the-public-sector.pdf adresinden alınmıştır. [Erişim Tarihi 29.02.2020]

Reed, K. (2001). The Use of Correspondence Analysis to Develop a Scale to Measure Workplace Morale from Multi-Level Data, Social Indicators Research, 57(3), 339-351.

Robbins, M.L., Karan, A. (2020). Who Gossips and How in Everyday Life? Social Psychological and Personality Science, 11(2), 185-195.

Robinson, S.L., Bennett, R.J. (1995). A Typology of Deviant Workplace Behaviors: A Multidimensional Scaling Study, Academy of Management Journal, 38(2), 555-572.

Rooks, G., Tazelaar, F., Snijders, C. (2011). Gossip and Reputation in Business Networks, European Sociological Review, 27(1), 90-106. 
E. Bilginoğlu - U. Yozgat 12/3 (2020) 2592-2610

Root, G.N. (2020). Leadership Morale Strategies. http://smallbusiness.chron.com/leadership-moralestrategies-16909.html. adresinden alınmıştır. [Erişim Tarihi 05.03.2020]

Ros, A.J. (2001). Profits for All? The Cost and Benefits of Employee Ownership. New York: Nova Publishers.

Ruch, W.A. (1994). Measuring and Managing Individual Productivity. D.H. Harris (Ed.) Organizational Linkages: Understanding the Productivity Paradox içinde (105-130). USA: The National Academies.

Saunders, P.A. (1999). Gossip in an Older Women's Support Group: A Linguistic Analysis. H. E. Hamilton (Ed.) Language and Communication in Old Age: Multidisciplinary Perspectives içinde (267-294). New York: Garland Publishing.

Schwantes, M. (2017, January 25). 9 Ways to Get Rid of Workplace Gossip Immediately. https://www.inc.com/marcel-schwantes/if-you-do-these-things-you-qualify-as-a-gossiper-whichresearch-says-can-ruin-yo.html adresinden alınmıştır. [Erişim Tarihi 15.01.2020]

Simms, A. (2013, April). The Private Sector is More Efficient than The Public Sector. https://b.3cdn.net/nefoundation/78cfe0444c38b5b9d0_3hm6iyth8.pdf adresinden alınmıştır. [Erişim Tarihi 05.03.2020]

Steers, R.M., Mowday, R.T., Shapiro, D.L. (2004). The Future of Work Motivation Theory. Academy of Management Review, 29(3), 379-387.

Steinhage, A., Cable, D., Wardley, D. (2017, March 20). The Pros and Cons of Competition Among Employees. https://hbr.org/2017/03/the-pros-and-cons-of-competition-amongemployees\#: :text=Some\%20research\%20studies\%20suggest\%20such,effort\%20and\%20enables\%20hi gher\%20performance. adresinden alınmıştır. [Erişim Tarihi 15.01.2020]

Stern, D., Stone, J. R., Hopkins, C., McMillion, M. (1990). Quality of Students' Work Experience and Orientation Toward Work, Youth ve Society, 22(2), 263-282

Tabachnick, B., Fidell, L. (2012). Using Multivariate Statistics. London: Pearson.

The International Bank for Reconstruction and Development (1996). World Development Report 1996: From Plan to Market. New York: Oxford University Press.

Therrien, D. (2004, November 22). Rid Your Office of Backstabbers, Canadian Business, 77(23), 109-110.

Trendowicz, A., Ross Jeffery, R. (2014). Software Project Effort Estimation: Foundations and Best Practice Guidelines for Success. Switzerland: Springer.

Turner, M.M., Mazur, M.A., Wendel, N., Winslow, R. (2003). Relational Ruin or Social Glue? The Joint Effect of Relationship Type and Gossip Valence on Liking, Trust, and Expertise, Communication Monographs, 70(2), 129-141.

UNDP Global Centre for Public Service Excellence (2015). Is the Private Sector More Efficient? A Cautionary Tale. https://www.undp.org/content/undp/en/home/librarypage/capacity-building/global-centre-forpublic-service-excellence/efficiency.html adresinden alınmıştır. [Erişim Tarihi 05.03.2020]

van Iterson, A., Waddington, K., Michelson, G. (2011). Breaking the Silence: The Role of Gossip in Organizational Culture. N.M. Ashkanasy, C.P.M. Wilderom ve M.F. Peterson (Ed.) The Handbook of Organizational Culture and Climate içinde (375-392). Thousand Oaks, CA Sage.

Vélez Vega, A. (2017). A Comparison Study of Organizational Rumors and Gossip, Engagement, and Generations in the Working Sector of Puerto Rico, Revista Interamericana de Psicología Ocupacional, 36(1), $50-62$.

Volcker, P. A. (1989). Leadership for America: Rebuilding the public service (Rep. of the National Commission on the Public Service). Washington, DC: National Commission on the Public Service.

Waddington, K. (2012). Gossip and Organizations. NewYork: Taylor ve Francis.

Waddington, K., Michelson, G. (2007). Analysing Gossip to Reveal and Understand Power Relationships, Political Action and Reaction to Change Inside. Paper for the CMS Conference, Manchester, July 2007. 
E. Bilginoğlu - U. Yozgat 12/3 (2020) 2592-2610

Wakeman, C. (2013). The Reality-Based Rules of the Workplace: Know What Boosts Your Value, Kills Your Chances and Will Make You Happier. San Francisco, CA: John Wiley ve Sons.

Weakliem, D.L., Frenkel, S.J. (2006). Morale and Workplace Performance, Work and Occupations, 33(3), 335361.

Wert, S.R., Salovey, P. (2004a). Introduction to the Special Issue on Gossip, Review of General Psychology, 8(2), 76-77.

Wert, S.R., Salovey, P. (2004b). A Social Comparison Account of Gossip, Review of General Psychology, 8(2), 122137.

West Virginia Employment Law Letter (2008, April 04). What Can HR Do About Workplace Gossip? https://hrdailyadvisor.blr.com/2008/04/04/what-can-hr-do-about-workplace-gossip/ adresinden alınmıştır. [Erişim Tarihi 05.03.2020]

Westen, R. (1996, July/August). The Real Slant on Gossip, Psychology Today, 29, 44-50.

Wilkie, D. (2020). Workplace Gossip: What Crosses the Line? https://www.shrm.org/resourcesandtools/hrtopics/employee-relations/pages/office-gossip-policies.aspx adresinden alınmıştır. [Erişim Tarihi 15.01.2020]

Wolmer, A.L. (2017, April 07). 5 Ways to Transform Work Gossip Into Positive Communication. https://www.entrepreneur.com/article/290522 adresinden alınmıştır. [Erişim Tarihi 15.01.2020]

Worthington, R.L., Whittaker, T.A. (2006). Scale Development Research: A Content Analysis and Recommendations for Best Practices, The Counseling Psychologist, 34(6), 806-838.

Wu, L.Z., Birtch, T.A., Chiang, F.F.T., Zhang, H. (2018). Perceptions of Negative Workplace Gossip: A SelfConsistency Theory Framework, Journal of Management, 44(5), 1873-1898.

Yakaboski, T. (2020, January 08). Reframing Gossip in the Workplace. https://www.insidehighered.com/advice/2020/01/08/how-manage-detrimental-aspects-workplacegossip-academe-opinion adresinden alınmıştır. [Erişim Tarihi 15.01.2020]

Zhou, A., Liu, Y., Su, X., Xu, H. (2019). Gossip Fiercer than a Tiger: Effect of Workplace Negative Gossip on Targeted Employees' Innovative Behavior, Social Behavior and Personality: An International Journal, 47(5), e5727

Zimmerman, E. (2008, February 03). Gossip Is Information by Another Name. https://www.nytimes.com/2008/02/03/jobs/03career.html adresinden alınmıştır. [Erişim Tarihi 15.01.2020] 